\title{
Sentido da Vida e Conceito de Morte em Estudantes Universitários: Um Estudo Correlacional
}

\author{
Thiago Antonio Avellar de Aquino \\ Ana Carolina Diniz Alves \\ Andrei Alves de Aguiar \\ Rossana Ferreira de Oliveira Refosco \\ Universidade Federal da Paraíba
}

\begin{abstract}
RESUMO
Considerando a relevância da temática da finitude para a existência humana, este trabalho teve como objetivo conhecer as correlações entre o sentido da vida e as concepções acerca da morte. Participaram do estudo 190 estudantes universitários dos cursos de Direito, Educação Física, Fisioterapia e Psicologia, sendo a maioria destes participantes do sexo feminino (68,9\%), e de religião católica $(61,6 \%)$. Como instrumentos para a coleta de dados, foram utilizados o Teste Propósito de Vida, o Questionário de Percepção de Morte e um questionário sociodemográfico. Os resultados apontaram para a existência de correlações positivas entre o vazio existencial e as visões de morte como fracasso, dor e solidão, e abandono. Por outro lado, o vazio existencial correlacionou-se negativamente com a visão de morte como fim natural. Tais resultados apóiam a concepção teleológica de Viktor Frankl quando pressupõe que a consciência da finitude põe em movimento a vontade de encontrar um sentido para a vida. Conclui-se que variáveis existenciais são relevantes para compreender as concepções que as pessoas têm sobre a morte.
\end{abstract}

Palavras-chave: sentido da vida; conceitos de morte; psicologia existencial.

\begin{abstract}
Meaning of Life and Conceptions about Death in College Students: A Correlational Study

Considering the importance of finitude for human existence, this paper aimed to investigate the relationships between meaning of life and conceptions of death. The participants of this study were 190 male and female university students, from Law, Physical Education, Physiotherapy and Psychology courses. Most of the participants were female $(68,9 \%)$ and Catholic $(61,6 \%)$. The Purpose in Life Test, the Death Perspective Questionnaire and a socio-demographic questionnaire were used to collect the data. The results showed positive correlations between existential emptiness and concepts of death as failure, pain and loneliness, and abandonment. On the other hand, existential emptiness was correlated negatively with the concept of death as a natural end. Such results support the teleological conception of Viktor Frankl, which asserts that the conscience of finitude puts in motion the will to find a life purpose. We conclude that existential variables are relevant to understand the conceptions people have about death.
\end{abstract}

Keywords: meaning of life; concepts of death; existential psychology.

O presente artigo discute as relações entre o sentido de vida e as visões de morte, tendo como questão norteadora uma antiga inquietação humana: a própria finitude. A partir do momento em que o homo patiens, isto é, o homem que sofre, tomou consciência da morte, ele iniciou suas reflexões acerca da vida e dos sentidos atribuídos à existência humana. Destarte, tornase pertinente averiguar as possíveis associações entre as variáveis aqui discutidas, com o intuito de clarificar como as pessoas percebem o significado da existência em função dos significados atribuídos à morte.

Pode-se constatar que as atitudes e as percepções sobre a morte sofreram grandes mudanças ao longo dos séculos, modificando, por conseguinte, a concepção da vida dos indivíduos (Ariès, 1977). De acordo com Moreira e Lisboa (2006), o ser humano sempre buscou desvelar os mistérios que envolvem questões acerca do destino final da vida, e os saberes filosófico 
e religioso se encarregaram de elaborar tais explicações. Já na modernidade, constata-se que o desejo de conhecer a morte tem como escopo dominá-la, e não mais aceitar esse acontecimento como parte do ciclo natural da vida (Kovács, 1992).

Segundo Kovács (1992), é por via da tradição cultural que os indivíduos adquirem concepções sobre a morte, e o morrer na sociedade ocidental, é um ponto central da existência humana, que geralmente está associada à tristeza e ao sofrimento. Historicamente, a morte foi percebida de diversas maneiras: na Idade Média, por exemplo, a morte era algo natural e esperado, possibilitando ao homem a oportunidade de morrer em seu leito, confortado por familiares e amigos. $\mathrm{O}$ que era temido era a morte súbita, pois privava o indivíduo de se preparar para a despedida final. Essa visão foi sofrendo transformações no decorrer dos séculos em razão de vários determinantes históricos e culturais (Boemer, 1986). Conforme Ariès (1977), nos séculos V e VI, a morte, vista como um fenômeno que fazia parte do cotidiano do ser humano, era concebida com pouca dramaticidade e com simplicidade. Nessa perspectiva, os familiares, amigos e mesmo as crianças ficavam em volta do caixão por vários dias, para um último adeus. Dessa maneira, no período medieval, a morte era um fenômeno doméstico. O moribundo se preparava para morrer e administrava a própria morte, ela não representava uma ruptura definitiva com relação à vida. Os cristãos viam a morte como a passagem para uma vida eterna, o que transmitia um sentimento de conforto. Nesse sentido, a morte era percebida apenas como uma separação temporária entre os familiares, pois prevalecia uma continuidade entre vivos e mortos (Ariès, 1977).

Enquanto isso, a percepção cristã, considerando a esperança de um reencontro com os entes queridos, via os sentimentos de dor e perda de forma amenizada. Ainda na Idade Média, surgem interrogações sobre a vida e a morte, sobre a ressurreição e a vida eterna, fazendo com que os indivíduos começassem a temer pela morte e a ter um amor pela vida. As concepções acerca da finitude foram se reformulando com o desenvolvimento e florescimento da burguesia, para a qual a separação corpo e alma, vida e morte se integram ao pensamento binário da cultura ocidental (Ariès, 1977). Para Rodrigues (1995) no mundo medieval a relação com o corpo era aberta, expansiva, indisciplinada, em oposição ao mundo burguês que transformou o corpo humano como um meio para a produção de bens. Este autor assevera que os cemitérios ocupavam o centro da cidade, pois os mortos não eram considerados como inconvenientes. Ariès (1977) mostra que com as mudanças no modo de vida social e econômico, a morte passa a ser exaltada e dramatizada, surgindo as cenas do choro e cerimoniais de luto.

Nos dias atuais, o tema da morte tornou-se um tabu. Assim, Spilka, Stout, Milton e Sizemore (1977) sugerem que os estudos sobre as visões de morte levem em conta suas diversas dimensões. Os mesmos indicam oito aspectos para compreender as diversas concepções da morte:

1. Dor e solidão: representa a morte como um momento de agonia, isolamento, miséria, angústia e solidão.

2. Vida do além: aponta uma imagem da morte como uma nova vida, plena de satisfação, felicidade, recompensa e união com Deus.

3. Indiferença: indica a morte como um fenômeno indiferente ao ser humano.

4. Desconhecida: apresenta a perspectiva da morte como incerteza, mistério e desconhecimento.

5. Abandono: imagina a morte como o abandono de entes queridos e como um momento para se sentir culpado.

6. Coragem: concebe a morte como uma oportunidade para demonstrar virtudes, no caso, enfrentar o último teste da vida.

7. Fracasso: indica a morte como algo que impede a realização do potencial pessoal, por exemplo, a realização de objetivos e sentido da vida.

8. Fim natural: sugere a morte como algo que faz parte do ciclo natural da vida.

Um estudo realizado por Nogueira e Pereira (2006) investigou como a religiosidade pode influenciar nas perspectivas de morte. Os autores concluíram que tanto os católicos como os agnósticos são os grupos que apresentam mais dúvidas a respeito da morte e que, quanto maior o nível de religiosidade, menor a perspectiva da morte como fracasso e maior como coragem.

$\mathrm{O}$ medo e a ansiedade da morte podem ser agravados quando o ser humano é acometido por questões existenciais, como pode ser demonstrado na pesquisa de Donovan (1993), que encontrou uma relação entre a ansiedade perante a morte e a escala de vazio existencial $(r=-0,34 ; p<0,05)$. Segundo Spilka, Stout, Milton e Sizemore (1977), as pesquisas evidenciam a associação entre morte e ansiedade devido à ênfase que a sociedade dá ao individualismo, ao progresso e à esperança.

Para Xausa (2003), enquanto o homem primitivo recorre ao mito e à magia, o homem moderno se des- 
nuda de toda concepção religiosa sobre a morte para resolução do confronto com a finitude. Entretanto, a morte, de uma forma ou de outra, como um fenômeno fatal e inevitável, provoca angústia no ser humano. Kovács (1992), por sua vez, aventa que a morte estaria associada ao medo: de morrer, do sofrer e da impotência; do receio do que vem após a morte, do julgamento divino e da perda das relações com os outros; medo da extinção, medo do desconhecido. A morte também pode evocar a pergunta pelo sentido da vida (Frankl, 1981/1990a), posto que a transitoriedade da existência humana poderia destituir a vida de um sentido ou de um "para que viver". Tal questão será desenvolvida no tópico a seguir.

\section{O ser humano e sua busca por um sentido}

O psiquiatra vienense Viktor Frankl foi o autor que mais se debruçou acerca do sentido da vida e das formas patogênicas da frustração existencial nas sociedades industriais, chegando a fundar uma nova escola de psicoterapia denominada Logoterapia e Análise Existencial. Segundo esta abordagem, o conceito de homem abrange tanto a sua natureza instintiva quanto a preocupação com valores (estéticos, éticos e religiosos) e com a busca de um sentido para a vida. Desta forma, além dos fenômenos psicofísicos, este autor coloca em foco a questão do espírito humano, ou seja, a tomada de posição, as decisões pessoais de vontade, intencionalidade, interesse prático e artístico, pensamento criativo, senso ético, etc. (Lukas, 1989).

Frankl definiu estas características como especificamente humanas, distinguindo os homens dos animais. No que concerne a sua etiologia, os humanos são provenientes da dimensão noética (espírito humano), dimensão esta diferente da somática e da psíquica (Lukas, 1989). Assim, a questão do sentido da vida torna-se um problema característico do homem, tendo apenas este a capacidade de experimentar a problemática do seu ser (Frankl, 1946/1989a).

Enquanto por um lado a busca de sentido empreendida pelo homem se constitui como uma motivação primária, por outro, o sentido é pessoal e situacional, pois só pode ser encontrado por uma determinada pessoa e em uma determinada situação específica (Frankl, 1946/1989a; 1946/1994). Entretanto, teóricos como Freud consideram a busca por um sentido como um epifenômeno, ou seja, como formação reativa ou, em outras palavras, um mecanismo de defesa. A esse respeito, Frankl declara:
Mas, pelo que toca a mim, eu não estaria disposto a viver em função dos meus "mecanismos de defesa". Nem tampouco estaria pronto a morrer simplesmente por amor às minhas "formações reativas", o que acontece, porém, é que o ser humano é capaz de viver $e$ até de morrer por seus ideais e valores. (Frankl, $1946 / 1994$, p. 92)

Para Fizzotti (1998), o ser humano se relaciona com o mundo de forma ativa, posto que possui a capacidade de se relacionar com ele de forma criativa. Nesse relacionamento, Viktor Frankl (1946/1994) apresenta três categorias de valores: o valor que permite ao homem agir no mundo (homo faber - valores de criação, produção); o valor que permite ao homem receber algo do mundo (homo amans - valores vivenciais, como amor, gratidão, amizade, beleza); e o valor que leva o homem a transformar as suas situações limites, de sofrimento em realizações (homo patiens valores atitudinais).

Não obstante, o mal-estar da civilização se constitui na perda de significados para viver, o que é denominado vazio existencial. No que diz respeito à etiologia deste transtorno, Frankl (1952/1990b) apontou duas perdas que a humanidade sofreu durante a sua evolução - a dos "instintos" e da "tradição". Os instintos orientam o comportamento dos animais, por meio de padrões fixos de comportamentos. Já o ser humano, ao desvincular-se da natureza exclusivamente instintiva, por meio da sua inserção na cultura, precisou construir por si próprio o seu agir no mundo; quanto à tradição, as pessoas antigas sabiam muito bem o que deveriam fazer de sua vida, pois os valores que eram transmitidos serviam de guias para suas ações, condicionando suas condutas (Frankl, 1972/1988). O homem moderno não sabe mais o que quer e o que deve fazer de sua existência. Desta forma, o ser humano renuncia a sua autenticidade e unicidade para seguir o que os outros fazem ou ordenam, tornando-se um joguete das forças do meio.

Como consequência, o homem perdeu alguns alicerces que serviam de sustentação para o seu comportamento, passando a agir de acordo com o que os outros fazem (conformismo), ou fazendo aquilo que as outras pessoas querem que ele faça (totalitarismo), frustrando a vontade de sentido. $\mathrm{O}$ vazio existencial manifesta-se por meio de um estado de tédio ou de uma neurose dominical, aquela espécie de depressão que se torna manifesta justamente quando a pessoa se encontra na ausência do labor. Outra consequência da frustração existencial é a eclosão exagerada da vontade do prazer e de poder (Frankl, 1946/1994). 


\section{O sentido da finitude}

Frankl (1978/1989b) concebe que a vida tem sentido independente da sua brevidade ou longevidade, e que o ser humano, de forma geral, questiona o sentido quando toma consciência da finitude de sua existência. Se as pessoas fossem imortais, poderiam adiar as suas escolhas até o infinito, destituindo de sentido a realização dos valores no momento presente. Destarte, a morte despertaria a consciência para utilizar o tempo de vida com responsabilidade, ou seja, respondendo à vida e realizando os sentidos do momento, pois o sentido da morte depende do sentido que a pessoa soube dar à vida. (Fizzotti, 1998). Frankl (1946/1994) admite que a morte seria um dos aspectos que poderia retirar o sentido da vida. Segundo este autor, a própria imprevisibilidade, com a qual ela persegue a vida, confere um caráter de urgência ao tempo do qual dispomos, fazendo com que nos encontremos nas mesmas condições do aluno que "sabe muito bem que um toque da campainha interromperá, a um certo ponto, o tempo que tem à disposição para terminar sua tarefa" (Frankl, 1946/1994, p. 111). Dessa forma, a finitude despertaria o senso de responsabilidade e isso conferiria à vida um sentido, posto que a morte torna a existência humana única e irreversível.

Entretanto, a postura do homem atual é a de negação da própria finitude, por isso submete-se a um ritmo acelerado de vida, caracterizado pela sua alta produtividade no âmbito pessoal, social, econômico. Consequentemente, quando toma consciência da morte, isso poderá desencadear o medo e angústia perante essa finitude. Segundo Inwood (2002), "o que importa não é o deixar de viver físico, mas a atitude em relação à própria morte durante a vida" (p. 117). Destarte, para Frankl (1946/1994) a finitude é que dá sentido à vida humana, posto que o passado se constitui como a dimensão mais segura do ser humano, pois nele o ser humano preserva todos os valores realizados em sua existência, saindo da transitoriedade para a perenidade. Assim, a transitoriedade traz consigo a responsabilidade das escolhas do ser humano juntamente com a consciência da transitoriedade das possibilidades em potencial.

Tendo em vista as considerações supracitadas, o objetivo da presente pesquisa foi identificar relações entre as visões de morte e o grau de percepção de sentido na vida. Mais especificamente, esta objetivou identificar de forma exploratória quais as visões de morte que poderiam se associar com os níveis de vazio e realização existencial em uma amostra de estudantes universitários.

\section{MÉTODO}

\section{Amostra}

Esta pesquisa foi realizada com uma amostragem por conveniência, junto a 190 estudantes universitários, sendo $68,9 \%$ do sexo feminino. Os entrevistados eram provenientes dos cursos de graduação em direito, educação física, fisioterapia e psicologia de uma instituição de ensino particular da cidade de João Pessoa (PB). A média de idade foi de 23,6 (DP = 7,0), com amplitude de 17 a 58 anos. Quanto à autoatribuição religiosa, $61,6 \%$ denominaram-se católicos, $18,3 \%$ evangélicos, $5,3 \%$ espíritas, $10,5 \%$ nenhuma e $4,2 \%$ outras.

\section{Instrumentos}

Questionário de Percepção de Morte. Foi originalmente construído por Spilka, Stout, Minton e Sizemore (1977), adaptado por Barros-Oliveira e Neto (2004), possuindo 43 itens que variam segundo o grau de valor do participante: 1 = discordo totalmente; 2 = discordo; 3 = discordo um pouco; 4 = nem concordo nem discordo; $5=$ concordo um pouco; $6=$ concordo e $7=$ concordo totalmente. A escala possui oito fatores com os seus respectivos alfa de Cronbach, que são: morte como sofrimento e solidão $(\alpha=0,83)$; morte como além da vida e recompensa $(\alpha=0,94)$; indiferença em face da morte $(\alpha=0,84)$; morte como desconhecido $(\alpha=$ $0,86)$; morte como abandono $(\alpha=0,83)$; morte como coragem $(\alpha=0,83)$; morte como fracasso $(\alpha=0,87)$ e morte como um fim natural $(\alpha=0,78)$.

Teste Propósito de Vida (Pil Test). Este instrumento foi originalmente elaborado por James C. Crumbaugh e Leonard T. Maholich (1964) e revisado por Harlow, Newcomb e Bentler (1987) constituindo a versão Pil-R. Esta última versão se constitui de uma escala de tipo Likert, composta por 20 itens que se propõem a verificar fundamentalmente o nível de vazio existencial e de sentido de vida dispostos em uma escala de avaliação de sete pontos, com os extremos $1=$ discordo totalmente e $\mathbf{7}=$ concordo totalmente. Os itens desta escala contemplam os seguintes aspectos: propósito na vida, satisfação com a própria vida, liberdade, medo da morte, ideias suicidas e se a vida vale a pena. Estudos prévios indicam uma boa consistência interna, medida através do alfa de Cronbach, de 0,88 (Feldman \& Snyder, 2005).

Questionário sociodemográfico. Foi utilizado um conjunto de itens com a finalidade de obtenção de características sociodemográficas da população estu- 
dada. O instrumento contém questões relativas ao sexo, idade, escolaridade, estado civil e religião.

\section{Procedimentos éticos}

O projeto foi previamente submetido à apreciação do comitê de ética em pesquisa da Universidade Estadual da Paraíba, tendo sido aprovado sob o protocolo 0020.0133.000-09. Durante a execução do mesmo, foram salvaguardados todos os procedimentos éticos para realização de pesquisas com seres humanos, previstos na resolução 196/96 do Conselho Nacional de Saúde (CNS).

\section{Procedimentos para a coleta de dados}

A coleta de dados foi realizada de forma coletiva, em sala de aula, após a permissão do professor. Os estudantes receberam instruções de como responder ao questionário e foram informados da não obrigatoriedade da participação do estudo. Após assinarem o termo de consentimento livre e esclarecido, os respondentes começaram a responder aos instrumentos que foram anexados em formato de caderno. O tempo médio de resposta foi de 25 minutos.

\section{Procedimentos para a análise dos dados}

Os dados foram tabulados no programa estatístico SPSS, versão 16.0 e posteriormente foi verificada a fatorabilidade das escalas, bem como as suas precisões através do alfa de Cronbach. Após este procedimento, realizou-se o teste de correlação de Pearson.

\section{RESULTADOS}

Tendo em vista que as escalas aqui utilizadas são pouco conhecidas, no contexto em que foram aplicadas, optou-se inicialmente em verificar as propriedades psicométricas das mesmas.

\section{Escala das visões de morte}

Inicialmente, para a observação dos resultados das visões de morte, verificou-se a adequação de se realizar uma análise fatorial no conjunto de 43 itens que compõem a escala, o que foi confirmado através dos índices de $\mathrm{KMO}=0,77$; e o teste de Esfericidade de Bartlett, $x^{2}(300)=3854,59, p<0,0001$. Dessa forma, procedeu-se a uma análise dos componentes principais com rotação varimax, fixando-se o número de oito componentes.

Conforme a Figura 1, a escala parece ser multidimensional. Assim, oito componentes atenderam ao critério Kaise, apresentando eigenvalues superiores a 1. Já o critério de Cattell, indicado na Figura 1, sugere a presença de oito componentes, parecendo plausível assumir uma estrutura com oito componentes, o que juntos explicam 58,84\% da variância total (Tabela 1).

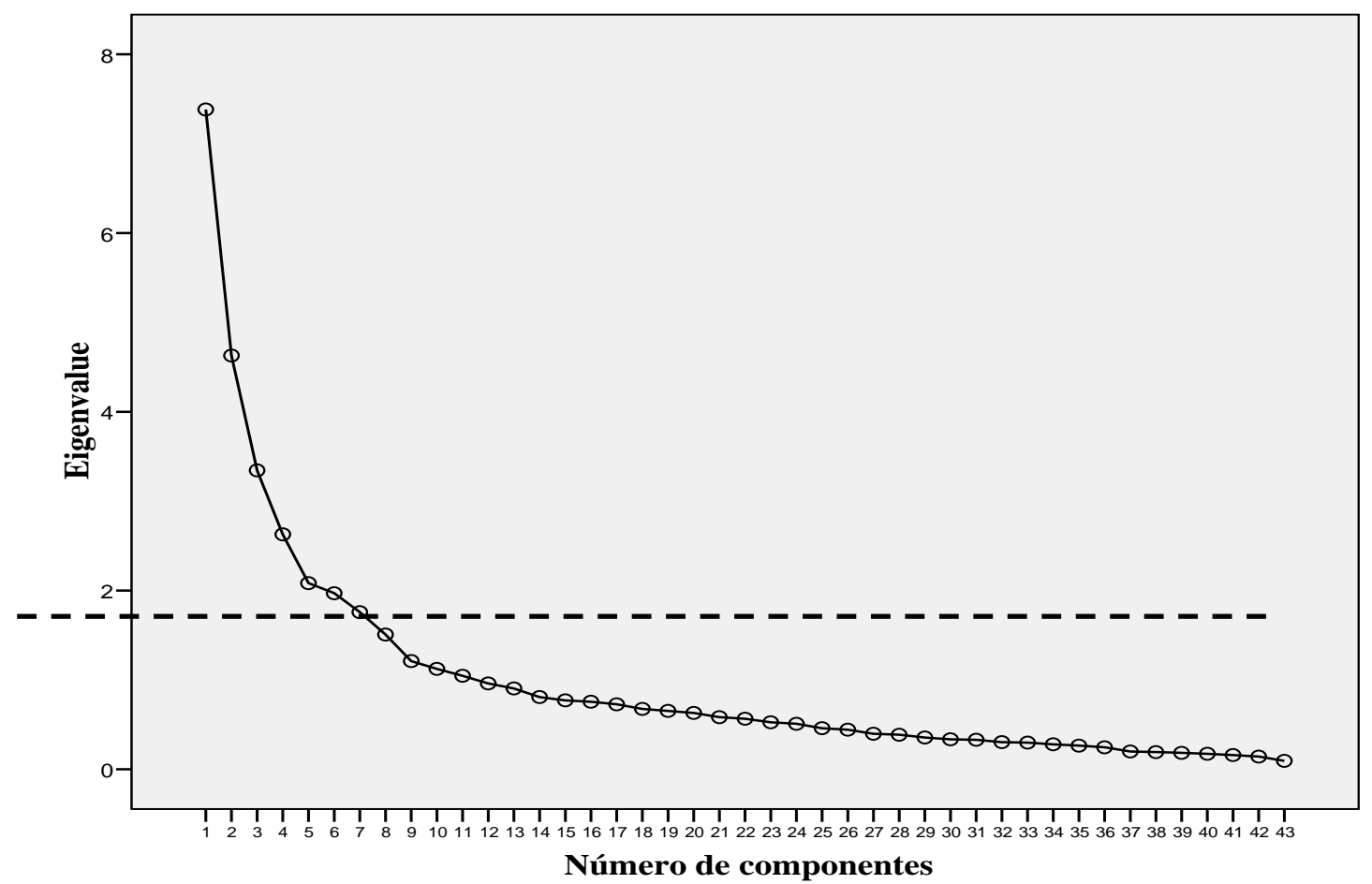

Figura 1. Representação gráfica dos eigenvalues da escala de visões de morte. 
Tabela 1

Estrutura fatorial da escala de visões de morte

\begin{tabular}{|c|c|c|c|c|c|c|c|c|}
\hline \multirow{2}{*}{ Conteúdo dos Itens } & \multicolumn{8}{|c|}{ Componentes } \\
\hline & I & II & III & IV & V & VI & VII & VIII \\
\hline 09. A própria ressurreição e recompensa. & $0,81^{*}$ & 0,70 & $-0,22$ & 0,98 & 0,06 & 0,05 & 0,11 & 0,17 \\
\hline 08. Um limpar e renascer de si mesmo. & $0,74^{*}$ & 0,13 & $-0,63$ & 0,17 & 0,59 & $-0,19$ & 0,82 & 0,60 \\
\hline 12. A porta de entrada no céu e felicidade plena. & $0,77^{*}$ & $-0,93$ & 0,17 & 0,22 & 0,53 & $-0,49$ & 0,12 & 0,05 \\
\hline $\begin{array}{l}\text { 11. Oportunidade de deixar esta vida em troca de outra } \\
\text { melhor. }\end{array}$ & $0,76^{*}$ & $-0,16$ & 0,26 & $-0,12$ & 0,13 & $-0,30$ & 0,11 & $-0,03$ \\
\hline 07. A entrada num lugar de total satisfação. & $0,73^{*}$ & 0,07 & $-0,08$ & 0,14 & 0,08 & $-0,01$ & $-0,07$ & 0,04 \\
\hline 10. União com Deus e eterna ventura. & $0,71^{*}$ & 0,05 & 0,09 & 0,22 & 0,13 & $-0,09$ & 0,12 & $-0,01$ \\
\hline 19. O maior dos mistérios. & 0,13 & $0,84^{*}$ & 0,08 & 0,03 & 0,13 & $-0,04$ & 0,13 & 0,01 \\
\hline 22. Um ponto de interrogação. & $-0,10$ & $0,80^{*}$ & 0,10 & 0,04 & $-0,01$ & 0,15 & 0,13 & 0,12 \\
\hline 21. Algo sobre que devemos dizer "não sei". & $-0,01$ & $0,78^{*}$ & 0,06 & $-0,03$ & $-0,03$ & 0,21 & $-0,11$ & 0,12 \\
\hline 18. A maior das incertezas. & $-0,04$ & $0,75^{*}$ & 0,04 & $-0,04$ & 0,03 & $-0,17$ & 0,06 & 0,14 \\
\hline 20. O fim do conhecido e o principio do desconhecido. & 0,10 & $0,67^{*}$ & 0,13 & 0,07 & 0,01 & 0,20 & 0,12 & $-0,12$ \\
\hline 23. A maior ambiguidade entre as complexidades da vida. & 0,07 & $0,65^{*}$ & 0,17 & 0,25 & 0,10 & 0,09 & 0,10 & 0,12 \\
\hline 25. Abandonar aqueles que amamos. & 0,04 & 0,10 & $0,73^{*}$ & 0,07 & $-0,01$ & 0,17 & 0,14 & $-0,19$ \\
\hline $\begin{array}{l}\text { 26. Razão para se sentir culpado por não poder } \\
\text { continuar a ajudar a família. }\end{array}$ & 0,02 & 0,07 & $0,73^{*}$ & 0,18 & 0,01 & 0,28 & $-0,15$ & 0,18 \\
\hline 28. Deixar a família entregue à sorte. & 0,11 & 0,02 & $0,69^{*}$ & 0,06 & 0,01 & 0,19 & $-0,18$ & 0,01 \\
\hline 27. Razão para se sentir culpado. & $-0,01$ & 0,14 & $0,65^{*}$ & 0,10 & 0,06 & 0,10 & $-0,21$ & 0,21 \\
\hline $\begin{array}{l}\text { 24. Deixar os que dependem de nós sujeitos às dificuldades } \\
\text { da vida. }\end{array}$ & 0,10 & 0,17 & $0,59^{*}$ & $-0,05$ & 0,07 & $-0,03$ & 0,14 & 0,12 \\
\hline 35. Um acontecimento que impede realização do potencial. & $-0,02$ & 0,10 & 0,49 & 0,06 & 0,18 & 0,40 & 0,13 & $-0,05$ \\
\hline 32. Uma oportunidade para uma grande realização. & 0,39 & $-0,02$ & $-0,09$ & $0,75^{*}$ & 0,04 & 0,06 & $-0,04$ & 0,06 \\
\hline 33. Um tempo para recusar a humilhação e a derrota. & $-0,06$ & $-0,08$ & 0,11 & $0,69^{*}$ & 0,19 & 0,09 & 0,03 & 0,07 \\
\hline $\begin{array}{l}\text { 34. Um teste ao compromisso em relação aos valores } \\
\text { pessoais da vida. }\end{array}$ & 0,10 & 0,08 & 0,20 & $0,68^{*}$ & 0,20 & 0,02 & 0,23 & $-0,06$ \\
\hline 31. Um grande momento de verdade para si mesmo. & 0,42 & 0,03 & $-0,01$ & $0,62^{*}$ & 0,14 & $-0,01$ & 0,17 & $-0,06$ \\
\hline $\begin{array}{l}\text { 29. Uma oportunidade para provar que lutamos por algo na } \\
\text { vida. }\end{array}$ & 0,24 & 0,25 & 0,16 & $0,58^{*}$ & $-0,03$ & 0,05 & $-0,01$ & 0,14 \\
\hline $\begin{array}{l}\text { 30. Uma ocasião para mostrar como podemos enfrentar o } \\
\text { último teste da vida. }\end{array}$ & 0,37 & 0,18 & 0,02 & 0,49 & 0,16 & 0,16 & 0,16 & 0,01 \\
\hline 05. A última angústia e tormento. & 0,20 & $-0,02$ & 0,04 & $-0,07$ & $0,79^{*}$ & 0,13 & 0,03 & 0,10 \\
\hline 01. O último momento de agonia. & 0,21 & 0,11 & 0,07 & $-0,04$ & $0,72^{*}$ & 0,12 & 0,07 & 0,04 \\
\hline 04. O destino de cair na beira da estrada. & 0,04 & 0,05 & $-0,09$ & 0,28 & $0,69^{*}$ & 0,14 & $-0,09$ & 0,24 \\
\hline 03. A última miséria. & $-0,03$ & $-0,07$ & 0,15 & 0,18 & $0,66^{*}$ & 0,07 & $-0,11$ & 0,10 \\
\hline 02. O fim de um tempo de isolamento. & 0,02 & 0,10 & 0,05 & 0,24 & $0,63^{*}$ & $-0,01$ & $-0,08$ & 0,11 \\
\hline 37. O fracasso pessoal na procura do sentido da vida. & $-0,05$ & 0,06 & 0,18 & 0,08 & 0,03 & $0,77^{*}$ & $-0,10$ & 0,08 \\
\hline $\begin{array}{l}\text { 38. A destruição da última oportunidade de plena realiza- } \\
\text { ção. }\end{array}$ & $-0,06$ & 0,04 & 0,32 & $-0,02$ & 0,24 & $0,75^{*}$ & 0,06 & 0,02 \\
\hline $\begin{array}{l}\text { 39. A derrota na luta por ser bem sucedido e alcançar os } \\
\text { objetivos. }\end{array}$ & $-0,08$ & 0,08 & 0,08 & 0,21 & 0,14 & $0,72^{*}$ & $-0,02$ & 0,08 \\
\hline 36. O fim das nossas esperanças. & $-0,09$ & 0,09 & 0,28 & $-0,22$ & 0,06 & $0,59^{*}$ & 0,10 & 0,12 \\
\hline 06. Uma experiência de solidão. & 0,17 & 0,29 & $-0,17$ & 0,23 & 0,36 & 0,40 & $-0,04$ & 0,06 \\
\hline 41. $O$ ato final de harmonia com a existência. & 0,19 & 0,16 & 0,04 & 0,20 & $-0,07$ & 0,30 & 0,25 & 0,10 \\
\hline 42. Um aspecto natural da vida. & 0,10 & 0,05 & $-0,08$ & 0,03 & $-0,06$ & 0,02 & $0,90^{*}$ & 0,06 \\
\hline 43. Parte do ciclo da vida. & 0,12 & 0,13 & $-0,09$ & 0,12 & $-0,06$ & $-0,03$ & $0,85^{*}$ & 0,06 \\
\hline $\begin{array}{l}\text { 40. Uma experiência que chega a todos devido à passagem } \\
\text { natural do tempo. }\end{array}$ & 0,14 & 0,134 & 0,05 & 0,14 & $-0,04$ & 0,05 & $0,70^{*}$ & $-0,09$ \\
\hline 16. Nem temida nem bem-vinda. & $-0,05$ & 0,17 & 0,18 & $-0,11$ & 0,15 & $-0,02$ & 0,22 & $0,68^{*}$ \\
\hline 17. Coisa indiferente de uma forma ou de outra. & $-0,03$ & 0,11 & 0,25 & 0,10 & 0,15 & $-0,05$ & $-0,06$ & $0,68^{*}$ \\
\hline 15. Algo pelo que devemos ficar indiferentes e esquecer. & $-0,03$ & 0,16 & $-0,15$ & $-0,03$ & 0,13 & 0,12 & $-0,13$ & $0,67^{*}$ \\
\hline 13. Pouco importante tendo em conta todo o resto. & 0,13 & $-0,08$ & $-0,02$ & 0,07 & $-0,06$ & 0,27 & 0,01 & $0,66^{*}$ \\
\hline 14. De poucas consequências. & 0,05 & 0,01 & 0,11 & 0,08 & 0,15 & 0,10 & 0,05 & $0,60^{*}$ \\
\hline Número de Itens & 6 & 6 & 6 & 6 & 5 & 5 & 3 & 5 \\
\hline Eigenvalue & 7,3 & 4,6 & 3,4 & 2,7 & 2,1 & 2,0 & 1,8 & 1,5 \\
\hline \% de variância explicada & 17,2 & 10,0 & 7,8 & 6,2 & 4,9 & 4,6 & 4,1 & 3,5 \\
\hline Alfa de Cronbach (a) & 0,85 & 0,86 & 0,77 & 0,79 & 0,79 & 0,78 & 0,80 & 0,72 \\
\hline
\end{tabular}

Nota. * $[0,50]$ (carga fatorial mínima considerada para interpretação dos componentes). Identificação dos componentes: I= vida do além; II = desconhecido; III = abandono; IV = coragem; V = dor e solidão; VI = fracasso; VII = fim natural e VIII = indiferença.

O primeiro componente reuniu seis itens, com saturação variando de 0,81 (a própria ressurreição e recompensa) a 0,71 (união com Deus e eterna ventura).
Apresentou valor próprio de 7,3; explicando 17,2\% da variância total. A consistência interna deste fator foi aferida através do alfa de Cronbach, que resultou num 
coeficiente de 0,85 , denominando este componente vida do além.

O segundo componente agrupou seis itens, com saturação de 0,84 (o maior dos mistérios) a 0,65 (a maior ambiguidade entre as complexidades da vida). Seu valor próprio foi de 4,6 e explicou $10 \%$ da variância total. A consistência interna deste fator (alfa de Cronbach) foi de 0,86 , sendo concebido como desconhecido.

O terceiro componente agrupou cinco itens, tendo a saturação de 0,73 (abandonar aqueles que amamos) a 0,59 (deixar os que dependem de nós sujeitos às dificuldades da vida). Seu valor próprio foi de 3,4 explicando $7,8 \%$ da variância. A consistência interna (alfa de Cronbach) foi 0,77 , sendo esse componente denominado de abandono.

O quarto componente reuniu cinco itens, com saturação de 0,75 (uma oportunidade para uma grande realização) a 0,58 (uma oportunidade para provar que lutamos por algo na vida). Seu valor próprio foi de 2,7 explicando $6,2 \%$ da variância. Seu alfa de Cronbach foi de 0,79 , concebido como coragem.

O quinto componente também reuniu cinco itens, com saturação de 0,79 (a última angústia e tormento) a 0,63 (o fim de um tempo de isolamento). Seu valor próprio foi de 2,1 e explicou $4,9 \%$ da variância. Seu alfa de Crombach foi de 0,79 e foi denominado esse componente dor e solidão.

O sexto componente reuniu quatro itens, com saturação que variam de 0,77 (o fracasso pessoal na procura do sentido da vida) a 0,59 (o fim das nossas esperanças). Seu valor próprio foi de 2,0 explicando 4,6\% da variância. Seu alfa de Cronbach foi de 0,78. Esse componente foi denominado fracasso.
O sétimo componente agrupou três itens, com saturação variando de 0,90 (um aspecto natural da vida) a 0,70 (uma experiência que chega a todos devido à passagem natural do tempo) - tendo como valor próprio 1,8; explicando $4,1 \%$ da variância. Seu alfa de Crombach foi de 0,80 , sendo esse componente concebido como fim natural.

O oitavo componente agrupou cinco itens, com saturação variando de 0,69 (nem temida nem bemvinda) a 0,60 (de poucas consequências). Seu valor próprio foi de 1,5 , explicando $3,5 \%$ da variância. $\mathrm{O}$ seu alfa de Crombach foi de 0,72 , sendo denominado indiferença.

\section{Escala do sentido de vida}

Para a averiguação da análise dos resultados do sentido da vida, verificou-se a adequação de se realizar uma análise fatorial no conjunto de 20 itens que compõem a escala, o que foi confirmado através dos índices de $\mathrm{KMO}=0,76$, e o teste de Esfericidade de Bartlett foi de $\mathrm{x}^{2}(190)=779,56, p<0,001$. Desta forma, procedeu-se a uma análise dos componentes principais com rotação varimax sem fixar o número de dimensões a priori.

Embora o gráfico scree plot sugira uma estrutura com três componentes (Figura 2), os pesquisadores optaram por uma estrutura mais parcimoniosa, considerando a escala como unifatorial, como sugere o estudo realizado por Aquino e cols. (2009). Assim, o componente atendeu ao critério Kaise, apresentando eigenvalues superiores a quatro. Destarte, parece plausível assumir uma estrutura com um componente, o que explica 20,45\% da variância total (Tabela 2). 


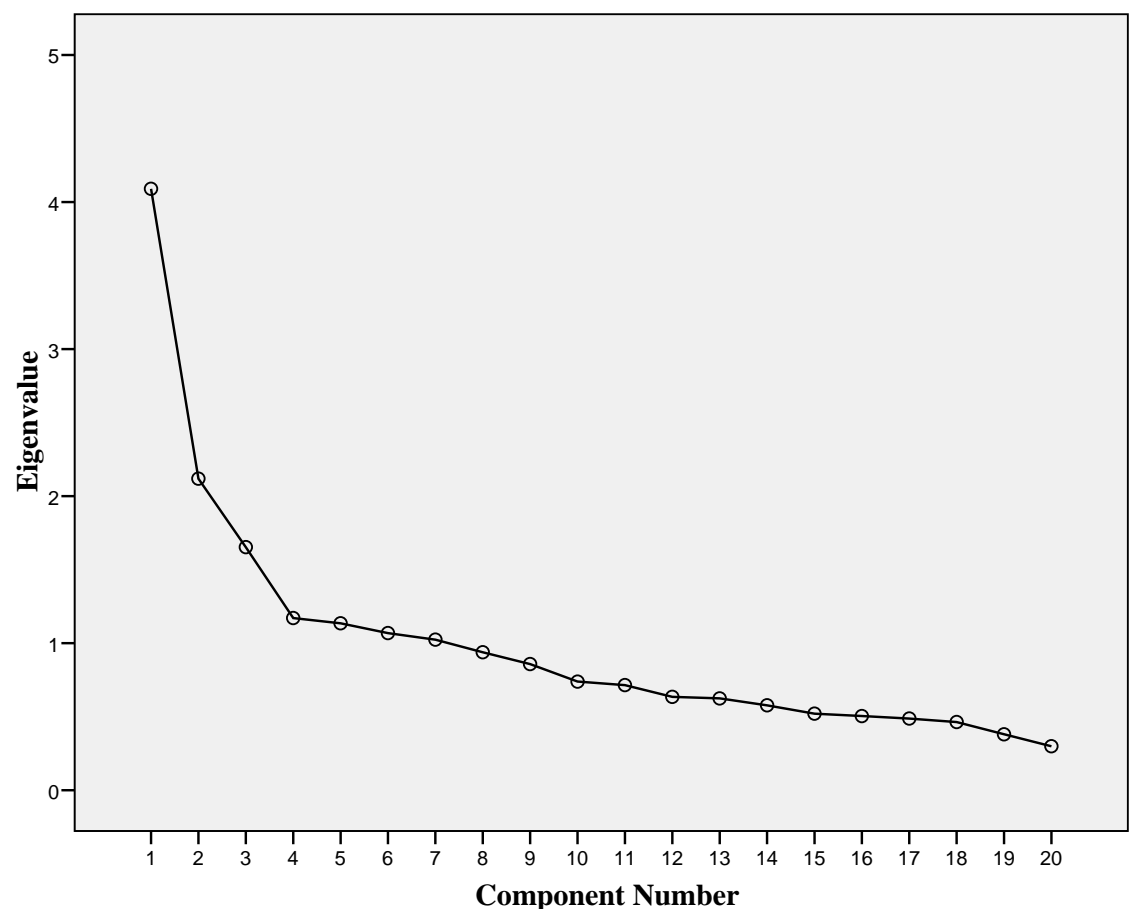

Figura 2. Representação gráfica dos eigenvalues da escala propósito de vida.

Tabela 2

Estrutura fatorial da escala Propósito de Vida

Conteúdo dos Itens

Vida

09. Minha vida é vazia preenchida só com desespero Carga Fatorial

06. Se eu pudesse escolher, preferiria nunca ter nascido

08. Quanto a alcançar metas na vida, não tenho feito nenhum progresso

02. A vida para mim parece sempre empolgante

03. Tenho na vida metas e objetivos muito claros

$-0,59^{*}$

20. Não descobri qualquer missão ou propósito na vida

$-0,59^{*}$

10. Se eu morresse hoje, sentiria que minha vida foi muito valiosa

05. Todo dia é constantemente novo

04. Minha experiência pessoal é inteiramente sem sentido ou propósito

$-0,53^{*}$

16. Quanto ao suicídio, tenho pensado seriamente ao seu respeito como uma saída

19. Encarar minhas tarefas diárias é uma fonte de prazer e satisfação

01. Geralmente estou completamente aborrecido

13. Eu não sou uma pessoa muito responsável

12. Considerando o mundo em relação a minha vida, o mundo deixa-me totalmente confuso

07. Após a aposentadoria, faria algumas coisas empolgantes que sempre quis fazer

15. Quanto à morte, estou preparado e sem medo

14. Quanto à liberdade do homem para tomar suas próprias decisões, acredito que o homem é totalmente livre para fazer todas
as escolhas da vida

$\begin{array}{ll}\text { 11. Ao pensar em minha vida, frequentemente penso por que existo } & 0,08\end{array}$

17. Considero as possibilidades de encontrar um sentido, um propósito ou missão em minha vida como muito grande $\quad 0,03$

\begin{tabular}{lr} 
18. Minha vida está em minhas mãos e eu a controlo & 0,02 \\
\hline
\end{tabular}

$\begin{array}{lr}\text { \% da variância explicada } & 20,45\end{array}$

Nota. ${ }^{*}[0,30]$ (carga fatorial mínima considerada para a interpretação do componente). 
O componente da escala de sentido de vida agrupou 14 itens, com saturação variando de 0,69 (minha vida é vazia, preenchida só com desespero) a 0,34 (considerando o mundo em relação a minha vida, o mundo deixa-me totalmente confuso) - apresentando valor próprio de 4,1 , explicando $20,45 \%$ da variância.
A consistência interna aferida através do alfa de Cronbach foi de 0,79 .

\section{Matriz correlacional}

Após definir as variáveis do estudo, procurou-se verificar as relações existentes entre as escalas de visões de morte e sentido (Tabela 3 ).

TABELA 3

Matriz correlacional entre vazio existencial e visões de morte

\begin{tabular}{|c|c|c|c|c|c|c|c|c|}
\hline 1. Vazio Existencial & 1 & & & & & & & \\
\hline 2. Vida do além & $-0,08$ & 1 & & & & & & \\
\hline 3. Desconhecido & 0,13 & 0,11 & 1 & & & & & \\
\hline 4. Abandono & $0,18^{*}$ & 0,10 & $0,25^{\star *}$ & 1 & & & & \\
\hline 5. Coragem & 0,06 & $0,49^{* * *}$ & $0,18^{*}$ & $0,20^{* *}$ & 1 & & & \\
\hline 6. Dor e solidão & $0,21^{* *}$ & $0,22^{\star *}$ & 0,13 & $0,17^{*}$ & $0,30^{\star * *}$ & 1 & & \\
\hline 7. Fracasso & $0,27^{\star \star *}$ & $-0,07$ & $0,21^{* *}$ & $0,42^{\star \star *}$ & 0,10 & $0,27^{\star \star *}$ & 1 & \\
\hline 8. Fim natural & $-0,19^{* *}$ & $0,24^{* *}$ & $0,21^{* *}$ & $-0,01$ & $0,21^{* *}$ & $-0,03$ & 0,01 & 1 \\
\hline \multirow[t]{2}{*}{ 9. Indiferença } & 0,14 & 0,01 & $0,22^{* *}$ & $0,22^{\star *}$ & $0,14^{*}$ & $0,30^{\star * *}$ & $0,24^{* *}$ & 0,01 \\
\hline & 1 & 2 & 3 & 4 & 5 & 6 & 7 & 8 \\
\hline
\end{tabular}

Nota. $p<0,05^{*} ; p<0,001^{* *}, p<0,0001^{* * *}$.

A Tabela 3 apresenta uma matriz correlacional entre as variáveis do estudo. Não obstante, analisaram-se apenas as correlações pertinentes ao objetivo do estudo. Desta maneira, constata-se uma correlação positiva entre vazio existencial e abandono $(r=0,18$; $p<0,05)$, vazio existencial e dor e solidão $(r=0,21$; $p<0,001)$ e vazio existencial e fracasso $(r=0,27$; $p<0,0001)$. Além disso, observou-se uma correlação negativa entre o vazio existencial e a morte como fim natural $(r=-0,19 ; p<0,001)$.

\section{DISCUSSÃO DOS RESULTADOS}

A presente pesquisa teve como escopo principal investigar as relações entre a percepção de sentido na vida e as visões de morte. Considerando-se que o objetivo foi atingido, é necessário pontuar que os resultados aqui encontrados devem ser considerados apenas no que se referem aos sujeitos investigados, visto que a amostra foi constituída exclusivamente por estudantes universitários.

Inicialmente verificou-se a fatorabilidade dos instrumentos da pesquisa, que foram considerados satisfatórios, apresentando bons parâmetros psicométricos, o que pode ser plenamente constatado por meio da consistência interna dos fatores, medida por meio do Alfa de Crombach, que variaram de 0,72 a 0,85 . A adaptação dos instrumentos a uma amostra brasileira sugeriu uma versão mais reduzida de ambos os testes.
A escala das perspectivas da morte foi reduzida a trinta e nove itens, enquanto o Teste Propósito de vida foi reduzido a quatorze itens.

De forma específica, a visão de morte como fracasso (o fracasso pessoal na procura do sentido da vida, a destruição da última oportunidade de plena realização, a derrota na luta por ser bem sucedido e alcançar os objetivos e o fim das nossas esperanças) se correlacionou diretamente com o vazio existencial ( $r=0,26, p<0,001)$. Segundo Fizzotti (1998), o homem não se contenta apenas em estar no mundo, mas deseja configurar uma vida com sentido. É plausível conceber que as pessoas que menos se encontram realizadas existencialmente podem temer a morte por esta não thes dar qualquer possibilidade de encontrar, no futuro, um sentido para as suas vidas. Comparando os sujeitos que apresentam maior realização existencial com aqueles que atravessam um período de vazio existencial, é possível perceber que nestes últimos a morte pode ser concebida como uma variável que causa a perda do sentido da vida.

A morte como dor e solidão (a última angústia $e$ tormento, o último momento de agonia, o destino de cair na beira da estrada, a última miséria e o fim de um tempo de isolamento) foi associada ao vazio existencial $(r=0,25 ; p<0,001)$. Essa associação é justificada quando Frankl (1952/1990b) argumenta que o nada que o homem teme está dentro dele mesmo, assim, ele estaria fugindo de si mesmo, o que seria uma 
fuga da solidão. Para as pessoas mais realizadas em seus sentidos de vida, a morte é concebida com um menor grau de dor e solidão, pois, quando o passado e o presente são percebidos como plenos de realização, a morte não retira o sentido da vida humana (Frankl, 1978/1989b).

A morte como fim natural (um aspecto natural da vida, parte do ciclo da vida e uma experiência que chega a todos devido à passagem natural do tempo) se correlacionou negativamente com o vazio existencial $(r=-0,20 ; p<0,001)$. Segundo Fizzotti (1998), diante da morte o homem se torna um indivíduo impossibilitado de evitá-la, o que o poderia levar a um estado de paralisia; no entanto, a morte gera no ser humano uma busca de sentido, pois a vida é constituída de diversos fatos que passam a possuir um significado importante para ele, lembrando-o de que o fim da vida está inserido na realidade humana.

Por outro lado, as pessoas fixam o seu olhar apenas na facticidade da morte e na transitoriedade da vida, se esquecem de contemplar os acontecimentos do seu passado, suas alegrias, seus atos criativos, bem como o sofrimento enfrentado com bravura, ou seja, os valores concretizados no passado.

Isso é ilustrado por Frankl com a seguinte comparação:

A pessoa que enfrenta ativamente os problemas da vida é como um homem que, dia após dia, vai destacando cada folha do seu calendário e cuidadosamente a guarda junto às precedentes, tendo primeiro feito no verso alguns apontamentos referentes ao dia que passou. É com orgulho e alegria que ele pensa em toda riqueza contida nas anotações. (Frankl, 1946/1994, p. 106)

Por fim, a visão de morte como abandono (abandonar aqueles que amamos, deixar a família entregue à sorte, razão para se sentir culpado por não poder continuar a ajudar a família, razão para se sentir culpado e deixar os que dependem de nós sujeitos às dificuldades da vida) se correlacionou positivamente com o vazio existencial $(r=0,19 ; p<0,001)$. Este resultado corrobora o pensamento de Frankl (1946/ 1994), quando aventa que todo medo da morte é, em última instância, um temor da consciência. Tal temor, segundo esse autor, diz respeito a todas as oportunidades que foram desperdiçadas na vida.

A questão do sentido de vida é algo inerente ao homem, pois ele possui a capacidade de questionar sobre a sua existência: sobre a sua vida e sobre a sua morte (Frankl, 1946/1989a). Para aqueles acometidos por um maior nível de vazio existencial, é maior a percepção da morte como algo negativo. A morte aparentemente retira o sentido da existência (Frankl, 1946/1994), pois uma percepção positiva da morte depende também do sentido que o ser humano encontra na própria vida e na própria morte (Fizzotti, 1998). Assim, a forma com que os estudantes investigados perceberam a finitude se associou com o grau de percepção de sentido na vida.

\section{CONSIDERAÇÕES FINAIS}

A presente pesquisa contribuiu para ajudar a sustentar empiricamente os conceitos teóricos que Frankl concebeu a partir da sua prática clínica. Este tipo de estudo serve não apenas para confrontar a teoria com os dados empíricos, mas também avança nas concepções construídas por este autor no século XX. Nessa direção, quando Frankl pergunta se a morte não retira o sentido da vida, ele não leva em conta as diversas dimensões das visões de morte, o que foi prontamente o foco de interesse da pesquisa aqui exposta.

Outra contribuição que se considera relevante é a identificação do tipo de visão de morte que está associada com o grau de realização e o de vazio existencial. Das oito visões apenas quatro se relacionaram ao nível de sentido: abandono, dor e solidão, fracasso e fim natural. Entretanto, para atender o critério de generalização dos resultados, sugere-se que estudos futuros possam dar suporte às correlações aqui encontradas. Para tanto, além de replicar a pesquisa, recomenda-se também ampliar a amostra para a população geral, considerando uma maior amplitude de idade, classe social e ocupação, bem como uma escala que possa medir o nível de religiosidade presente nos sujeitos, visto que a visão de morte está presente nas diversas expressões religiosas.

\section{REFERÊNCIAS}

Aquino, T. A. A., Correia, A. P. M., Marques, A. L. C., Souza, C. G., Freitas, H. C. A., Araújo, I. F., Dias, P. S., \& Araújo, W. F. (2009) Atitude religiosa e sentido da vida: Um estudo correlacional. Psicologia: Ciência e Profissão, 29, 228-243.

Ariés, P. (1977). História da morte no ocidente (P. V. Siqueira, Trad.). Rio de Janeiro: Francisco Alves.

Barros-Oliveira, J. B., \& Neto, F. (2004). Validação de um instrumento sobre diversas perspectivas da morte. Analise Psicológica, 2, 355-367.

Boemer. M. (1986). A morte e o morrer. São Paulo: Cortez.

Crumbaugh, J. H., \& Maholich, L. T. (1964). The psychometric approach to Frankl's concept of noogenic neurosis. Journal of Clinical Psychology, 20, 200-207.

Donovan J. M. (1993). Validation of a Portuguese form of Templer's death anxiety scale. Psychological Reports, 73, 195-200. 
Feldman, D. B., \& Snyder, C. R. (2005). Hope and the meaningful life: Theoretical and empirical associations between goaldirected thinking and life meaning. Journal of Social and Clinical Psychology, 24, 401-421.

Fizzotti, E. (1998). Abraham Maslow e Viktor E. Frankl: Os ritos de cura como auto-realização e como busca de sentido (C. B. Dalla Costa, Trad.). Em A. N. Terrin (Org.), Liturgia e terapia: A sacralidade a serviço do homem na sua totalidade (pp. 235275). São Paulo: Paulinas.

Frankl, V. E. (1988). La voluntad de sentido (M. J. Eckel, Trad.). Barcelona: Herder. (Original publicado em 1972)

Frankl, V. E. (1989a). Psicoterapia e sentido da vida (A. M. Castro, Trad.). São Paulo: Quadrante. (Original publicado em 1946)

Frankl, V. E. (1989b). Um sentido para a vida: Psicoterapia $e$ humanismo (V. H. S. Lapenta, Trad.). São Paulo: Santuário. (Original publicado em 1978)

Frankl, V. E. (1990a). A questão do sentido em psicoterapia (J. Mitre, Trad.). Campinas: Papirus. (Original publicado em 1981)

Frankl, V. E. (1990b). Psicoterapia para todos: Uma psicoterapia coletiva para contrapor-se à neurose coletiva (A. Allgayer, Trad.). Petrópolis: Vozes. (Original publicado em 1952)

Frankl, V. E. (1994). Em busca de sentido: Um psicólogo no campo de concentração ( $4^{\mathrm{a}} \mathrm{ed}$.) (W. O. Schlupp \& C. C. Aveline, Trad.). Petrópolis, RJ: Vozes. (Original publicado em 1946)
Harlow, L. L., Newcomb, M. D., \& Bentler, P. M. (1987). Purpose in life test assessment using latent variable methods. British Journal of Clinical Psychology, 26, 235-236.

Inwood, M. (2002). Dicionário Heidegger (L. B. Holanda, Trad.). Rio de Janeiro: Jorge Zahar.

Kovács, M. J. (1992). Morte e desenvolvimento humano. São Paulo: Casa do Psicólogo.

Lukas, E. (1989). Logoterapia: A força desafiadora do espírito Métodos de logoterapia (J. S. Porto, Trad.). São Paulo: Loyola/ Leopoldianum.

Moereira, A. C., \& Lisboa, M. T. L. (2006). A morte - entre o público e o privado: Reflexões para a prática profissional de enfermagem. Revista de Enfermagem UFRJ, 14, 447-454.

Nogueira, D., \& Pereira, L. (2006). Perspectivas da morte de acordo com a religiosidade: Estudo comparativo. Retirado em 30 de junho de 2008 de http://psicologia.com.pt/artigos/ textos/TL0058.pdf

Rodrigues, J. C. (1995). Higiene e ilusão. Rio de Janeiro: Nau.

Spilka, B., Stout, L., Minton, B., \& Sizemore, D. (1977). Death and personal faith: A psychometric investigation. Journal for the Scientific Study of Religion, 16, 169-178.

Xausa, I. A. M. (2003). O sentido dos sonhos na psicoterapia em Viktor Frankl. São Paulo: Casa do Psicólogo.

Recebido: 29/01/2010

Última revisão: 04/06/2010

Aceite final: 20/06/2010

\section{Sobre os autores:}

Thiago Antonio Avellar de Aquino: Psicólogo, Doutor em Psicologia Social pela Universidade Federal da Paraíba, Professor da Universidade Federal da Paraíba (Departamento de Ciências das Religiões).

Ana Carolina Diniz Alves: Psicóloga do Centro de Referência Especializado em Assistência Social, Santa Luzia (PB).

Andrei Alves de Aguiar: Psicólogo graduado pelo Centro Universitário de João Pessoa. Mestrando em Ciências das Religiões pela UFPB.

Rossana Ferreira de Oliveira Refosco: Psicóloga do Centro de Atenção Psicossocial II, Santa Rita (PB).

Endereço para correspondência: Universidade Federal da Paraíba - Campus I - Centro de Educação - Departamento de Ciências das Religiões - 58051-900 João Pessoa/PB. Endereço eletrônico: logosvitae@ig.com.br. 